\title{
Argumentative Bluff in Eristic Discussion: An Analysis and Evaluation
}

\author{
Jan Albert van Laar
}

Published online: 18 April 2010

(C) The Author(s) 2010. This article is published with open access at Springerlink.com

\begin{abstract}
How does the analysis and evaluation of argumentation depend on the dialogue type in which the argumentation has been put forward? This paper focuses on argumentative bluff in eristic discussion. Argumentation cannot be presented without conveying the pretence that it is dialectically reasonable, as well as, at least to some degree, rhetorically effective. Within eristic discussion it can be profitable to engage in bluff with respect to such claims. However, it will be argued that such bluffing is dialectically inadmissible, even within an eristic discussion.
\end{abstract}

Keywords Argumentative bluff · Eristic discussion - Critical discussion · Dialogue types · Fallacies

\section{Introduction}

According to a widely accepted view in the theory of argumentation, we need to investigate the circumstances of an argument in order to be able to understand and evaluate the argument adequately. An argument is typically put forward by a particular speaker to particular addressees in a particular kind of situation. One component of this 'situatedness' or 'contextuality' is the type of dialogue in which the argumentation is presented. What is the role of dialogue types when explaining, reconstructing and evaluating argumentative moves?

Walton and Krabbe (1995) distinguish six basic types of dialogue based on more elementary distinctions pertaining to the initial situation of a dialogue, the individual aims of the participants and the collective main goal of the dialogue. These six types are persuasion dialogue, negotiation dialogue, eristic dialogue,

\footnotetext{
J. A. van Laar $(\bowtie)$

Department of Theoretical Philosophy, University of Groningen, Oude Boteringestraat 52,

9712 GL Groningen, The Netherlands

e-mail: j.a.van.laar@rug.nl
} 
inquiry dialogue, deliberation dialogue and information-seeking dialogue. In addition, they acknowledge so-called mixed types, such as debate. This paper restricts its scope to what is only a subtype of eristic dialogue, namely eristic discussion. ${ }^{1}$ An eristic discussion (also referred to as 'sophistical dialogue' by Walton 1998, p. 195) forms a highly adversarial and competitive kind of conversation where each party attempts to create the impression that he or she is the most clever and skilful discussant in a shared attempt to determine an appropriate intellectual hierarchy between them. Suppose an argument is situated in an eristic discussion. Of what consequence is this when attempting to explain, reconstruct and evaluate elements of the discourse?

Following this introduction, Sect. 2 will deal with the issue of the role that dialogue types play when analysing and evaluating arguments. The upshot will be that we need a descriptive kind of model, including a descriptive account of the minimal normativity inherent in an eristic discussion, in order to be able to explain eristic phenomena. However, when it comes to the reconstruction and evaluation of argumentation we need to start from a normative model, such as a model of critical discussion, and the norms that happen to govern eristic discussion need not be particularly useful for developing the reconstruction and evaluation. Nevertheless, for the purpose of reconstruction and evaluation a descriptive account of the eristic discussion will be considered useful insofar as it prepares the analyst for the problems and fallacies that can be expected in this type of context. After offering a descriptive characterization of eristic discussion in Sect. 3, this characterization is used to explain a typically eristic phenomenon, that of so-called argumentative bluff, in Sect. 4. A number of guidelines for evaluating argumentative bluff will be presented in Sect. 5 .

\section{Analysing and Evaluating Eristic Argumentation}

Are dialogue types just descriptive models of conversational contexts where argumentation can be expected, or are they, in addition, models with which to evaluate arguments? Walton proposes dealing with models of types of dialogue both as descriptions of kinds of dialogue and as normative models. In his view, argumentation that is situated within a particular dialogue type must be evaluated by determining to what extent the former serves the main goal of the latter.

[W]hen an argument is used it is a good argument (or a successful or correct argument) to the extent that it contributes to the goal of the dialogue. But there can be different goals because there can be different types of dialogue in which the same argument can be used. Thus in the new dialectical method of evaluating arguments, an argument is correct or reasonable if it is used at some stage in a dialogue to contribute to the overall goal of that type of dialogue by fulfilling the requirements for the kind of move an argument is supposed to be at that stage. (Walton 1998, p. 30)

\footnotetext{
${ }^{1}$ The other subtype of eristic dialogue, discussed by the authors in more detail than eristic discussion, is the quarrel (Walton and Krabbe 1995, pp. 76-79; Walton 1998).
} 
For example, Walton and Krabbe (1995, p. 79) state that '[i]n the eristic discussion, an outrageous fallacy may be the best and most successful technique to persuade your audience'. In the light of Walton's contention that an argument in an eristic discussion is reasonable if it contributes to the goal of the eristic dialogue, this suggests that the eristic context makes an otherwise fallacious move non-fallacious.

Suppose we come across an argument or a different kind of contribution to an argumentative dialogue and we start wondering whether this argument or contribution is fallacious rather than legitimate. If the context is that of an eristic discussion, we might be enticed into thinking that this suspect argument or contribution is less problematic or less fallacious, given the eristic context, than a similar argument or move put forward in a more cooperative kind of dialogue. Why would we think so? One answer could be that, as a matter of fact, the parties are not really engaged in a serious resolution-oriented discussion. If the conversation is eristic, the norms for critical discussion seem to be far-fetched and irrelevant to an evaluation of what the disputants are doing. They are not collectively attempting to achieve a resolution of their differences, rather they are outmanoeuvring one another in a verbal match. Applying rules for critical discussion therefore, would be like applying the rules of a dance contest to a wrestling match, or so the critique might go. Two reasons weigh against this position.

First, when we are interested in the quality of argumentation, we are justified in employing a model for what we, the analysts of the argumentation, consider ideally to be reasonable argumentation. For, when we aim at an evaluation, we must interpret and reconstruct the discourse by using the notions and terms that we used when developing and formulating our argumentative norms, in order to be capable to subsequently apply these norms to the moves thus reconstructed. I start from the assumption that critical discussion (van Eemeren and Grootendorst 2004, chapters 3 and 6) is the best existing model of dialectically reasonable argumentation. Given this assumption we must distil those elements of the discourse that are relevant, either positively or negatively, to the resolution of the underlying differences of opinion. Consequently, even if a disputant is not consciously concerned with, and makes no pretence to argumentative reasonableness, this does not count against the appropriateness of the decision to reconstruct and evaluate his or her contributions from the stance of what we consider as reasonable argumentation. In this way, even wrestling might be fruitfully viewed from the stance of dancing. But, the norms even more clearly apply to contributions that do bring with them argumentative pretences. Even in an eristic discussion the participants maintain a pretence to reasonableness when putting forward an argument or an argumentative criticism. I consider this a matter of definition: presenting an argument or an argumentative criticism, among other things, conveys the pretence that this contribution is argumentatively reasonable. In order to determine whether a contribution lives up to its reasonableness pretence, we are justified to apply the conception of reasonableness that we consider to be the appropriate one, for the pretence of an arguer is that the contribution satisfies the correct requirements of reasonable contributions, and not the requirements that the language used happens to consider as the correct ones, whether correctly so or not. 
Second, in addition to an appeal to norms from such an external perspective, there is some ground for appealing to the normativity internal to an eristic discussion (for the distinction between external and internal normativity, see van Eemeren et al. 2010). If an eristic disputant puts forward a contribution with argumentative pretences, we cannot take for granted that he or she adopts the same norms of reasonable argumentation as we argumentation theorists do. Even if they do not share our conception of reasonableness, or they do not share it to a sufficient degree, the argument in the preceding paragraph shows that we are nonetheless justified in employing our notion of dialectical reasonableness when it comes to evaluating the argumentation. However, there is some ground to expect that the actual regulative ideal of reasonable argumentation held by a disputant who puts forward an argument is not completely different from the norms of critical discussion. While not focusing specifically on eristic contexts, extensive empirical research has been done which suggests that ordinary users of language employ similar norms of argumentative practice as those prescribed by the model of critical discussion (van Eemeren et al. 2009). I expect that ordinary language users will also be disposed to apply these norms, or pre-theoretical norms resembling them, when asked to evaluate eristic contributions that have a clear argumentative pretence. Thus, there is some ground for expecting a commitment to argumentative reasonableness, as we conceive of it, on the part of eristic disputants. For these two reasons, the rules of critical discussion can be applied to contributions brought forward in an eristic discussion.

Of course, a disputant can attempt to be rhetorically assertive, in the sense of emphasizing his or her rhetorical skills, even if doing so would be at the expense of the reasonableness of the contribution. Furthermore, the attending audience may happen to value such assertiveness higher than is desirable from an argumentative perspective, by assigning points to assertive moves that in effect contain violations of the norms of reasonable discussion. This, however, should not lure us into conflating the notions of assertiveness and reasonableness. We do not need to evaluate arguments in eristic discussion from the perspective of the main goal of eristic discussion and there is good reason for taking the model of critical discussion as the normative point of departure.

Given that I will reconstruct and evaluate eristic contributions from the perspective of critical discussion, the following question arises: When wanting to evaluate an argument, does it matter whether or not it is situated within an eristic discussion? In response, I consider two closely related views, that of van Eemeren and Houtlosser and that of Krabbe, both of which diverge from the view held by Walton but still assign an evaluative role to knowledge of the relevant argumentative activity or dialogue type.

Van Eemeren and Houtlosser defend the notion that argumentation must always be evaluated by determining to what extent it serves or hinders the goal of a genuine critical discussion, which is considered to be the resolution of a difference of opinion after having taken the merits of both sides into account. Nevertheless, they also hold that the evaluation of argumentation can be improved by considering the 
argumentative activity type ${ }^{2}$ that is, the type of institutional context in which the argumentation is located. First, knowledge of the argumentative activity can be used to reconstruct the discourse adequately, for example by enabling us to unearth the commitments of those involved (van Eemeren et al. 2010). Thus, it is because we know what role a prosecutor is supposed to play that we know that a particular question of him or her must be reconstructed as a premise in an argument. Second, the activity type can provide us with context-sensitive criteria with which it can be determined whether a discussion move complies with a general rule of critical discussion (van Eemeren et al. 2010). How the general norms of critical discussion are to be applied can depend on the features of an activity type. For example, the rules of critical discussion allow a discussant to employ a so-called pragmatic argumentation scheme. When using this scheme, the discussant argues for or against a course of action by pointing to the desirable or undesirable consequences of the course of action respectively. If the discussion is part of a parliamentary debate, the desirability most plausibly pertains to the interests of the public at large, while if the discussion is part of a mediation session between parents on the verge of a divorce, the desirability most plausibly pertains to the interests of the child. Thus, van Eemeren et al. (2010) contend that the context can provide a criterion with which to determine whether a consequence counts as desirable or not. To my mind, the idea of such context-sensitive criteria can be accommodated in the theory of critical discussion by reconstructing such criteria as contextual specifications of the norms of critical discussion that the participants can agree upon in the opening stage of a critical discussion. ${ }^{3}$ By entering into a particular argumentative activity type, a person is implicitly committed to such an outcome of the opening stage.

Krabbe (2009) holds that the normative model of critical discussion prescribes a high level of cooperation between the participants, while at the same time allowing the parties some level of competitiveness. Various dialogue types can be seen as forcing the participants to raise the level of cooperation beyond the level prescribed by a resolution-oriented critical discussion. ${ }^{4}$ For example, an inquiry or a deliberation dialogue requires participants to work more closely together in a shared attempt to reach an outcome that can either count as shared knowledge or as a course of action that is agreed upon. These additional norms can be applied when evaluating the argumentation. Again, these norms can be reconstructed as implicitly agreed upon by entering into an inquiry dialogue or deliberation dialogue. In other words, additional procedural starting points can be established by the participants in

\footnotetext{
${ }^{2}$ An argumentative activity type is a conventionalized entity that in principle can be identified through empirical observation (van Eemeren and Houtlosser 2005, p. 76).

${ }^{3}$ A critical discussion, as modelled by van Eemeren and Grootendorst (2004), is a normative procedure that passes through four stages. In the confrontation stage the parties express their initial positions. In the openings stage they decide upon propositions that can be used as basic premises and upon additional procedural points of departure. In the argumentation stage the protagonist attempts to defend a standpoint against the critical responses put forward by the antagonist. Finally, in the concluding stage, the parties decide whether the initial dispute has been resolved and, if so, in whose favour.

${ }^{4}$ Krabbe (2009) examines three ways in which this idea can be elaborated: by separate normative models for each kind of dialogue type; by one normative model that allows the parties more or less room for manoeuvring strategically, depending on the context; and by encompassing models that assign more or less competitive tasks to subordinate models.
} 
the opening stage of their discussion. Thus, both Krabbe (2009) and van Eemeren et al. (2010) assign a direct evaluative role to the dialogue (or argumentative activity) type in allowing the procedural commitments of the participants to be partly determined by the argumentative activity type. Thus, when evaluating argumentative discourse we can determine whether the argumentation follows both the general rules of critical discussion and the additional or specified norms agreed upon in the opening stage. ${ }^{5}$

The problem, however, is that this solution seems to work well for all dialogue types except the eristic, as a crucial characteristic of an eristic discussion is that there is less cooperation than prescribed by the norms of critical discussion and the contestants are typically unwilling to bind themselves to propositions or more detailed procedures. ${ }^{6}$

As will be shown in Sect. 4, a descriptive account of eristic discussion is useful when attempting to explain the occurrence of typically eristic phenomena. However, when reconstructing and evaluating argumentation that occurs in eristic contexts, a descriptive model of eristic discussion does not serve any direct evaluative purpose, as I have attempted to argue in this section. Nevertheless, I will attempt to show that such a descriptive account of eristic discussion is still useful for evaluative purposes in a more indirect way.

\section{Eristic Discussion}

What does it mean to say that two parties are engaged in an eristic discussion? The account that I will provide aims to give a description of the objectives and norms that play a role in this kind of conversation. Starting from the sketch presented by Walton and Krabbe (Walton and Krabbe 1995; Walton 1998), I will explicate the idea of eristic discussion as a game. Unlike Walton and Krabbe, I will examine a variant in which the game is performed in front of an audience that acts as a judge or jury. The extent to which this conceptual construal is useful for the study of particular aspects of antagonistic discourse will be a matter for further empirical research. ${ }^{7}$

\footnotetext{
${ }^{5}$ However, not every additional rule can be accepted as established through a legitimate decision in the opening stage. At the very least, the additional rule must not be inconsistent with the general rules of critical discussion.

${ }^{6}$ When eristic discussion takes place in the context of a further specific type of argumentative activity, for example a parliamentary debate, there could be institutional constraints that apply to the manoeuvring of the eristic disputants. In the Dutch parliament, for example, the disputants must always address the speaker of the house and not each other. It is more precise to state, therefore, that when a conversation becomes eristic, this shift does not bring additional constraints, while existing institutional constraints could remain operative after such a shift.

7 It will often be difficult to make a strong case for the claim that a particular conversation provides a clear example of an eristic discussion, due to the fact that this dialogue type is partly defined in terms of the objectives of the participants and that participants will often be reluctant to admit that these are their objectives. Nevertheless, the model provides a fruitful perspective on argumentation and dialogue insofar as it explains features of the discourse.
} 
Eristic discussion has been described by Walton and Krabbe as a dialogue between participants who start from an 'unsettled intellectual hierarchy' (Walton and Krabbe 1995, p. 78), who collectively attempt to 'settle the intellectual hierarchy' (Walton and Krabbe 1995, p. 79) and who individually aim to attack and defeat the other side by appearing to be verbally more skilful. They use Plato's Euthydemus as a prime example.

In my account, I focus on a contemporary variant of eristic discussion that usually takes place in front of a large audience. Prototypical examples can be found in heated exchanges between politicians who try to outmanoeuvre one another, supposing that a victory generates votes or other assets. ${ }^{8}$ Normally, an eristic discussion is part of a more complex kind of exchange that also contains fragments that must be considered as belonging to a negotiation dialogue, to an informationseeking dialogue, or to one of the other dialogue types. In parliamentary discussion, for example, all kinds of dialogue can be expected, with often one and the same move or segment of dialogue making a contribution to several of the dialogues that are running. If a politician points out that the voters will be likely to protest if the cabinet adopts a particular policy, this can be seen as contributing to a persuasion dialogue with respect to the desirability of adopting this policy, in this case by pointing out an undesirable consequence of the adoption of the policy, as well as contributing to a negotiation dialogue by putting pressure on the other side to comply with these demands, in this case by threatening that there will be protests. Some combinations of dialogue type are conventionalized to such a high degree that they can be seen as constituting a distinct, mixed type of dialogue. Walton and Krabbe (1995, pp. 83-84) discuss debate as a mixture of persuasion dialogue and eristic discussion, which is further characterized as being conducted before an audience. This paper is about the eristic component or dimension of debates and other political discussions. (As we will see, even from a purely eristic perspective, argumentation and reasonableness pretences are important. So, different from what Walton and Krabbe suggest, the existence of appeals to reasonableness in a debate is not only due to the circumstance that a debate has features of persuasion dialogue).

Following the results found in formal dialectic (Hamblin 1970; Mackenzie 1990; Krabbe and Walton 1995), I aim at a game-like model of eristic discussion, in this case a game that is played by two disputants in front of an audience. The audience serves as a jury, eager to discover who deserves to be declared the honourable winner. This paper only discusses some of the conceptual preliminaries.

The game starts with an antagonism between the two disputants, part of which are one or more so-called differences of opinion, such that the parties have avowed opposite positions regarding these issues. Another part of the antagonism is the lack of a fixed pecking order between the disputants as regards debating. Often, but not necessarily, the antagonism is loaded with emotion and the stakes are high.

The disputants can be strongly opposed and the eristic discussion quite chaotic. Nevertheless, there is a main goal that makes the skirmish into a type of

\footnotetext{
${ }^{8}$ Formal debating competitions offer a special kind of example, in which the stakes are mostly educational. A notion that is closely related to the eristic discussion is Tannen's agonism, described as 'ritualized adversativeness' (Tannen 2002, p. 1652).
} 
conversational game. (Of course, if the degree of chaos is too high, the exchange simply fails to be an eristic discussion, and plausibly even fails to be a conversation of any sort). Just as the shared goal of competing football teams is to fix the athletic hierarchy between them, the collective goal of an eristic discussion is to determine the intellectual hierarchy as regards the discussion of the topic at hand. Eristic discussion is the kind of game that aims to determine who is most capable, shrewd, smart and artful when it comes to devising and presenting arguments and criticisms. Thus, in eristic discussion, argumentation plays a vital role, even when it is clear that its final aim is not so much to be convincing as to be victorious. By entering the eristic discussion, the disputants commit themselves to the realization of this main goal. Consequently, even though an eristic discussion allows the participants plenty of elbowroom for vicious and deceptive tactics, there are a number of restrictions that must be taken into account. For example, a participant must be committed to giving the other side a chance to have their say, physical violence and open threats are inappropriate, each contribution must at least to some minimal degree be relevant to the difference of opinion that underlies the antagonism, lies are improper, and so on. Part of this internal normativity (cf. van Eemeren et al. 2010) involves the regulative rules to which disputants appeal when they offer arguments, and which they pretend to be in line with, conceiving them as the proper norms for reasonable argumentation.

In order to achieve the primary aim of determining who is the most skilful arguer, the individual aim of each disputant is to create the impression among the audience that he or she prevails. In order to create the impression of victory, each party tries to outmanoeuvre the adversary in an argumentative way. By thus testing the verbal and logical skills of the other side the parties further the main goal. Thus, the disputants' individual aims are in conflict, constituting the agonistic, polemical and adversarial nature of an eristic discussion.

Given that argumentation and criticism are understood as strategic manoeuvring between dialectical reasonableness and rhetorical persuasiveness (van Eemeren and Houtlosser 1999, 2002), the individual aim of a disputant in this eristic game is likewise complex, having a dialectical as well as a rhetorical component. The aim that can be attributed to the parties is not so much that of acting with genuine dialectical reason and real rhetorical success vis-à-vis the adversary addressed, but to create the impression in the judging audience that one's strategic manoeuvring is successful. ${ }^{9}$ Thus, the disputants exploit argumentation. It resembles the nature of an argument in a student's examination paper. The student does not try to convince the teacher of the acceptability of the argument's conclusion, but attempts to demonstrate that he or she is capable of presenting this kind of argument and has mastered the content of the curriculum. In eristic discussion, arguments are typically used in a similarly indirect manner in order to show one's dialectical reasonability

\footnotetext{
9 Note that I do not use the term strategic manoeuvring to refer to manoeuvring between the main aim of an eristic discussion and the main aim of an ideally reasonable discussion. As with pragma-dialectical theory, the term refers to manoeuvring between persuasion of the other side and resolution of the dispute on the merits of the arguments of both sides. The special feature of strategic manoeuvring in eristic discussion is that it is used for a further purpose, which is not inherently argumentative: to convince the audience to judge you as the triumphant party.
} 
and rhetorical assertiveness. I will deal with the two components of this manoeuvring in turn.

First, the aim of any disputant is to create the impression of being a reasonable arguer, that is, a person who offers dialectically reasonable argumentation, rather than to be reasonable. Depending on the circumstances and on the dispositions and prejudices of the audience, there can be several means available for producing this impression, varying from dressing in a particular manner to explicitly stating that one is exceedingly reasonable. However, if the audience has some critical acumen, the main device will be that of presenting argumentation of such a kind and in such a way that it creates the impression, correctly or not, of being reasonable. That this aim is present in an eristic discussion becomes apparent in the reproaches that characterize these dialogues. I will give a few examples. When accusing the other side of a bias, the message often is that the bias kept the arguer from giving sufficient weight to a counter consideration. When pointing out an inconsistency between words and deeds, one of the messages typically is that the arguer is dishonest whilst appealing in his argument to his trustworthiness. When showing that a policy defended by a politician is extremely unpopular, part of the message plausibly is that this lack of popularity makes the implementation of the proposed policy undesirable and that the politician has overlooked this counter argument. Thus, part of the analysis of these typically eristic moves is that they appeal to argumentative reasonableness. Consequently, eristic disputants must reckon with the impression of argumentative reasonableness when designing their own contributions.

Second, the aim of any disputant is to demonstrate that he or she is an assertive arguer, that is, to create the impression on the part of the audience that the argumentation is rhetorically effective and persuasive against one's eristic adversary. This is not exactly the same as the aim of choosing a rhetorically effective means of persuasion. The latter can be achieved by, for example, presenting arguments that happen to persuade the adversary addressed. The former is achieved when the audience comes to consider the disputant as having put forward rhetorically effective means of persuasion when addressing an adversary, whether the adversary is persuaded or not. Depending on circumstances, there can, again, be several means available for achieving the aim of assertiveness. Depending on the contextual specifics the impression of being an effective discussant might be served by divergent devices, such as showing mastery of a rhetorical trick, announcing that one possesses an effective persuasive strategy, announcing, again, one's reasonableness, or even stressing one's position as the underdog. Assertiveness can be demonstrated by more belligerent means, such as a personal attack, but in some situations and for some people the same result is better served by tactics that are seemingly more friendly, such as a show of political moderation and moral fairness. Note that working towards this aim is not fallacious per se. It can be expected that one of the main devices, if not the crucial device in the case of the audience having some critical acumen, will be that of presenting argumentation with which one appears, correctly or not, to be making progress towards convincing and winning over one's adversary. An eristic discussion, therefore, is a clash between disputants who attempt to create an image of argumentative reasonableness and 
assertiveness. Of course, the best strategy in eristic discussion is to choose those means of persuasion that serve both aims simultaneously, in which case the strategic manoeuvring is successful eristically (but not necessarily dialectically). However, these means can be absent, or hard to find.

The audience keeps the score and in the end declares the winner, unless it declares the discussion a draw. ${ }^{10}$ The audience also chooses from various criteria by which to decide who has won the game. Depending on the set of criteria chosen, we could distinguish variants of the eristic discussion. The audience may assign more weight to the degree of reasonableness exhibited by a disputant. This would steer the eristic discussion in the direction of a critical discussion. Or the audience may assign more weight to the rhetorical assertiveness exhibited by a disputant. In this case, the eristic discussion is pulled towards a verbal fight. The audience may even assign positive points to fallacious moves, and do so even when they see through these in cases where they take the fallacy to be evidence of the disputant's assertiveness.

Nevertheless, the value of rhetorical assertiveness cannot be stretched too far. A disputant who does not seem to be concerned with presenting an image of being a reasonable arguer and who, consequently, employs all kinds of illegitimate argumentative tricks in an attempt to gain the upper hand, undermines his or her own position. An argumentative strategy can only be a rhetorically effective strategy if it is presented under the pretence of being dialectically reasonable to a sufficiently high degree, for an obviously unreasonable arguer can hardly appear to be effective. The audience must have the impression that the adversary addressed ought to change their opinion for good reasons. This does not imply that a disputant needs to maintain the image of being a reasonable arguer at each juncture of the dialogue. The audience can appreciate fallacious tactics and assign the fallacy monger points for assertiveness, but only if these tactics can be considered to be part of a broader strategy that in essence or on the whole is considered genuinely dialectically reasonable. I will assume that we are dealing with a type of eristic discussion in such cases where the audience takes this latter approach, pushing the disputants to balance reasonableness and effectiveness in their overall performance, but not at the level of every single conversational contribution.

There are further choices to be made when deciding what counts as reasonable and effective in the eyes of the audience. For the sake of simplicity and also in order to make the game interesting for the purpose of studying argumentation from a normative perspective I will now add the following two assumptions. First, the audience adopts the pragma-dialectical concept of reasonableness that is specified in the model of critical discussion. ${ }^{11}$ Second, the audience only judges an argument (whether the argument is elementary, consisting of just one justificatory step, or whether it is complex, being a configuration of several elementary arguments) to be effective with respect to the adversary if in the end the adversary both accepts the

\footnotetext{
${ }^{10}$ I suspect that it is not unusual for members of audiences to make their decisions about who to vote for or about what opinion to adopt on the basis of their verdicts about who is the most skilful eristic disputant.

11 Note that my argument in favour of choosing the norms of critical discussion for the purpose of argument evaluation does not depend on this choice.
} 
basic premises of the argument and the justificatory force of each of the steps in the reasoning. ${ }^{12}$

As we saw above, argumentative dialogues are often complex, containing fragments that belong to distinct dialogue types. An example of a dialogical exchange that, among other things, also constitutes an eristic discussion can be found in the 2008 Dutch Parliamentary Debate on the Speech from the Throne, during which a member of parliament, Geert Wilders, addressed members of the cabinet and responded to criticism from his parliamentary colleagues. The exchange is rife with personal attacks of various kinds. For example, Wilders accused the members of most other parties of advocating multiculturalism for the personal motive of profiting from such policies in relation to their own or their friends' careers and for the partisan motive of creating a new voting group. His opponents, in turn, accused Wilders of being anti-Islamist in order to gain more support and votes. (Wilders is known for his provocative style of rhetorical assertiveness; his opponents often-but not always - couch their assertiveness in a style that exhibits moderation and fairness). In part, these personal attacks contribute to the kind of quarrel that informs the attending audience about the alleged biases and character flaws of the adversaries. However, what is of interest to this paper is that the personal attacks also clearly contribute to an eristic discussion, whereby each party tries to outwit the other in an attempt to triumph, or at least to survive, as an assertive - though not unreasonable-debater.

We now have a framework by which to explain the argumentative behaviour of the disputants in an eristic discussion. In such a vein, Walton and Krabbe explain the occurrence of a number of fallacies, such as ad hominem (Walton and Krabbe 1995, p. 111), straw man and irrelevancy (Walton 1998, p. 196) as the result of a shift from a persuasion dialogue to an eristic dialogue. In the following section I will elaborate on a specific strategic aspect of argumentation in eristic discussion, an aspect that is not found in a genuinely critical discussion. This explains a different characteristic of eristic discussion, namely what will be called argumentative bluff.

\section{Argumentative Bluff}

Argumentation and the pretence to reasonableness and effectiveness go together, as we have seen. If Party A conveys an argumentative pretence to something, then this can be understood as conveying the message that Party A will win the subdiscussion that would ensue from Party B's challenging this pretence. In the subdiscussion, Party A would have to substantiate the pretence. If Party A succeeds, the pretence apparently was justified, if not, Party A has apparently bluffed or blundered. Thus, the word 'pretence' is here not used in its pejorative sense but in the neutral sense of laying claim to something in a dialogue, whether or not that claim is correct. In the following I focus on the pretence to effectiveness, although what follows can also be applied to the pretence to reasonableness.

\footnotetext{
12 These basic components of effectiveness are also covered by the conditions of appropriateness for the speech act of advancing argumentation (van Eemeren and Grootendorst 1992).
} 
Argumentative pretences have a specific strategic flavour within the context of an eristic discussion. This is due to two interconnected features. First, the argumentation officially addresses the adversary in the sense that the arguer alleges to present argumentation that answers the questions and criticisms of the adversary. However, the ultimate judge is the attending audience. There is, as will be shown, reason for the arguer to think that the audience will accept the argumentative claims on his or her authority. Second, the dialogue is not primarily about the merits of the disputants' opinions but about their argumentative skills. As a consequence, there is a risk involved for any addressee who wishes to challenge a claim. These two features give rise both to bluffing when conveying argumentative pretences and to the avoidance of calling the opponent's bluff.

Characteristically, eristic discussions take place among politicians or other professional or experienced public speakers. The audience, however, is heterogeneous and mainly made up of laypersons, both with regard to the topic at hand and to the techniques of discussion. This makes the scorekeeping audience a potential target of the disputants, who allege to hold expert opinions on the issue of who is winning and who is losing. Thus, by pretending to be effective, a public speaker may often be seen as appealing to their own credibility as an experienced debater.

Suppose a disputant such as the Dutch politician Wilders argues that 'Each nonWestern immigrant family costs us 230,000 euros, therefore the multicultural project costs us 100 billion euros!'. ${ }^{13}$ Within the context of this debate, this argument suggests that a refusal to accept the conclusion must be due to a refusal to apply the universal laws of arithmetic to multiculturalist prejudices. The mere pretence to the argument being logically strong ${ }^{14}$ could increase the likelihood that the audience (those who read and watch the news) accepts that claim. It conveys the message to the audience, 'trust me, you can assign the points to me, as my opponent will not be able to challenge me successfully'. Such a pretence can also be strengthened. One way is to act as though the adversary has already accepted the claim, for example by using the argument to support a further argument. Another way is to act as though any challenge to the validity of the pretence would be a nonstarter or fallacious, for example by saying something like 'of course, the one thing implies the other'. The pretence can also be weakened, by adding terms or phrases such as 'probably'. We could call these strengthening and weakening devices. In such cases, the arguer can be seen to be engaged in eristic scorekeeping, marking, more or less firmly, a point on the audience's scoreboard in his or her own favour. In

\footnotetext{
13 This argument is contained, partly implicitly, in the following contribution by Wilders: 'That multicultural society is also a very expensive business. Thanks to a study by the Netherlands Bureau for Economic Policy Analysis (Centraal Planbureau) done a few years ago, we know that an average nonWestern immigrant family costs Dutch taxpayers $€ 230,000$. That is 100 billion in total. That is what the multicultural project costs, 100 billion. Think about what else we could have done with that money' (Dutch Parliamentary Debate on the Speech from the Throne, 17 September 2008, p. 53). He addressed these remarks, via the speaker of the house to the cabinet and the opposition members of parliament.

14 However, in fact, the reasoning is very weak, for non-Western immigrant families also generate money and other assets and it is not at all clear that these profits have been taken into account. The further suggestion that the multicultural project is expensive is also unjustified, for the costs are not compared to those of other groups, such as Western immigrant families or non-immigrant families. If these costs are relatively more expensive, the multicultural project might be considered a bargain.
} 
short, the presence of a judging audience consisting of laypeople enables a disputant to influence the score, not just by expressing the propositions that make up the argumentation but also by conveying the argumentative pretence of effectiveness.

Of course, this attempt to influence the audience would not work if the adversary challenged the pretence and thereby forced the arguer to substantiate the claims. So why would the arguer take the risk, hoping that the critic would remain silent and allow them to easily get away with the pretence? The answer I hypothesize is that in an eristic discussion there is also a risk involved in challenging pretences.

The primary aim of presenting argumentation is that of creating the appearance of being reasonable and effective. Suppose the adversary challenges an argumentative pretence to effectiveness, erasing, as it were, the score credited to the arguer. A sub-discussion will then ensue, resulting either in the arguer substantiating the claim or in the addressee substantiating the challenge. If the addressee succeeds in substantiating the challenge, this will improve his or her image as an assertive arguer (or as an assertive critic, for that matter). However, if the addressee fails to substantiate the challenge and is forced to withdraw it, this event will damage his or her image as an effective disputant. An unsuccessful criticism counts against the skills and strike-power of the addressee, who then becomes vulnerable to ridicule and contempt. The arguer increases the possible damage by having employed strengthening devices such as 'of course'. Such a strategic consideration on the part of the addressee does not play any role in a critical discussion, for the reason that a critical discussion is fully tailored to the promotion of criticism. There ought not to be any heavy penalty for unsuccessful criticism.

Thus, whether or not an addressee chooses to challenge an argumentative pretence will be the result of an estimation of the expected value of the act of challenging the pretence versus accepting the pretence. While accepting the pretence clearly leads to a particular loss for the addressee, challenging the pretence involves a risk: the critic assigns a particular probability and positive value to success, as judged by the audience, but also assigns a particular probability and negative value to possible failure, as judged by the audience. Depending on such considerations a choice must be made, and if the chance of failure or the cost of failure is too great, the better option will be to accept the limited loss that results from accepting the pretence.

Thus, in an eristic discussion, offering argumentation can be seen as the placing of a bet such that the adversary can choose to 'call the cards' and challenge the pretence, or 'pass', by refraining from making the call and thus accepting the loss. A speaker can be seen to be argumentatively bluffing when he or she intentionally conveys a false or unwarranted argumentative pretence. Given the addressee's risk of damaging his or her image, the strategy of bluffing can turn out positively for the arguer: there remains a real possibility that the arguer will get away with it, thereby improving his or her chances of receiving a positive verdict from the audience. Of course, a strategy of permanent bluffing will not be successful, for as soon as the critic discovers this he or she will know that challenging the pretence will be profitable. ${ }^{15}$ The arguer might raise the stakes by strengthening the pretence: 'Of

\footnotetext{
15 It would be interesting to examine strategies in eristic discussion from the perspective of game theory in order to determine the exact conditions under which bluffing is eristically rational.
} 
course, A implies B', or reduce the stakes by weakening the pretence: 'Probably, A implies B'. However, the addressee might also raise the stakes by responding to the argument with a phrase such as 'that's ridiculous', hoping for the arguer to then back down.

Thus, we have seen two interconnected explanations of the existence of argumentative bluff in eristic discussion: an audience is prone to accepting claims made by experienced debaters and the expected value of accepting a pretence can sometimes be greater than that of challenging it. This is part of the context within which the pretence to effectiveness must be understood. ${ }^{16}$

\section{Evaluating Bluff in Eristic Discussion}

From the perspective of the main goal of an eristic discussion, bluffing is right or legitimate insofar as it serves the purpose of establishing the appropriate hierarchy between the disputants. Here, however, we are concerned with the dialectical admissibility of argumentative bluffing. To what extent can bluffing be considered right from the perspective of resolving the differences of opinion on the merits of the case? In this section, I will sketch out a way of evaluating bluff. A more detailed evaluative account based upon the consideration of a number of real-life examples still has to be developed.

When bluffing pertains to the acceptability of the propositional content of argumentation, it can be analysed, in terms of pragma-dialectical theory, as a violation of the rule of critical discussion, according to which the false presentation of a proposition as a shared starting point is not permitted (van Eemeren and Grootendorst 2004, pp. 145-147, 193). When bluffing pertains to the justificatory connection between reasons and standpoint, the bluffing can be reconstructed as a violation of a rule that states, among other things, that the protagonist has successfully defended the justificatory force if the argumentation exemplifies a logical schema that has been accepted as valid or an argumentation schema that has been accepted as admissible (van Eemeren and Grootendorst 2004, pp. 148-150). ${ }^{17}$ This view can be summarized as stipulating that a party is not permitted to falsely present the propositional content as acceptable to the addressee or the justificatory force as sufficient within the context of the discussion. ${ }^{18}$ Thus, it is from the perspective of these norms that argumentative pretences are to be reconstructed and evaluated.

As we have seen, a theory of eristic discussion is not of direct relevance when evaluating arguments, for the reason that this type of argumentative activity does not bind the participants to additional material or procedural commitments. Nevertheless, it has a more indirect relevance because it prepares analysts (and the

\footnotetext{
16 The same reasoning can also be applied with respect to the pretence to reasonableness.

17 Given that a fallacy is defined as a violation of a rule of critical discussion, argumentative bluffing is fallacious, but not because it is done intentionally (van Eemeren and Grootendorst 2004, p. 175).

18 This is to be determined by following the intersubjective inference procedure in cases where the argumentation is presented as logically valid, or using the intersubjective testing procedure in cases where the argumentation is presented with less strict aspirations.
} 
participants who in their reflective moments adopt the role of analysts) for the types of problems and fallacies that can be expected in these kinds of circumstances.

(1) Given that parties are enticed to bluff now and then, an analyst should be on guard for the conveyance of argumentative pretences. Eristic discussion not only invites disputants to commit straw man and ad hominem fallacies but also to be strongly motivated to violate the starting point rule or one of the rules of justificatory force by argumentative bluffing.

(2) Given that parties are enticed to avoid calling the other's bluff, at least now and then, an analyst should be on guard for the lack of critical acumen displayed in the behaviour of the disputants. In this type of dialogue, critics can develop the intention to not challenge pretences they consider risky, also because silence cannot be criticized as readily as a fallacy. Nevertheless, there is a flaw in this strategy, related not so much to the violation of the rights of the other side, but to the fact that it is thought opportune to remain silent on a particular issue, thereby disregarding the duties of an antagonist to critically and systematically test the protagonist's position. ${ }^{19}$

(3) When evaluating a polemical discourse, the mere fact that the addressee does not respond to the claims of the speaker or writer should not be taken as a strong indication of this claim being acceptable. The 'silence means assent' assumption (cf. Mackenzie's use of this assumption in his formal dialogue systems, 1990) should not be taken for granted in this kind of context.

\section{Conclusion}

In this paper, I have worked towards a game-like model of the argumentative activity type of eristic discussion. The model needs further specification through rules with which the audience can determine the score. Such a model would be more complete and on this basis provide an experimental-like setup in which to study the strategic manoeuvring of discussants involved in arguing with and criticizing each other in such polemical situations. More specifically, I have used the descriptive model of eristic discussion in order to explain argumentative bluff. Even though the intrinsic normativity of an eristic discussion cannot be used when evaluating polemical argumentation from the dialectical perspective of dispute resolution, a clear grasp of what can be expected in this kind of situation still guides an evaluation by informing us about what to expect in this type of dialogue. A theory of eristic discussion might further prove helpful for developing an understanding of the means with which: (1) disputants can reshape circumstances in directions that are more congenial for genuine resolution-oriented discussion, and (2) audiences can be educated so that they can steer eristic discussion in the direction of a reasonable critical discussion.

\footnotetext{
19 The antagonist can then be said to have not behaved in conformity with one of two basic requirements for dialectical reasonableness, namely that one ought to try to win the critical discussion (the other requirement being to obey the rules, Krabbe 2001).
} 
Acknowledgments I would like to express my thanks to Erik Krabbe and the two anonymous reviewers of this journal for their comments on this paper. Parts of this paper were presented at the research colloquium of the Department of Speech Communication, Argumentation Theory and Rhetoric of the University of Amsterdam, at the conference Rhetoric in Society, January 2009 at Leiden University, and at the conference Argument Cultures, organized by the Ontario Society for the Study of Argumentation at Windsor, Ontario. I would like to thank the participants at these events, and especially George Boger, for their questions and suggestions. Sections 3 and 4 have been published in the proceedings of Rhetoric in Society. An earlier version of the paper will also be published in the proceedings of Argument Cultures.

Open Access This article is distributed under the terms of the Creative Commons Attribution Noncommercial License which permits any noncommercial use, distribution, and reproduction in any medium, provided the original author(s) and source are credited.

\section{References}

Hamblin, C.L. 1970. Fallacies. Virginia: Vale Press.

Krabbe, E.C.W. 2001. Strategies in dialectic and rhetoric. In Argumentation and its applications (CDROM, ISBN 0-9683461-2-X, Proceedings from the conference of the Ontario society for the study of argumentation, 17-19 May, 2001, University of Windsor, Windsor), ed. H.V. Hansen, C.W. Tindale, J.A. Blair, R.H. Johnson, and R.C. Pinto. Windsor: University of Windsor.

Krabbe, E.C.W. 2009. Cooperation and competition in argumentative exchanges. In Rhetoric and argumentation in the beginning of the XXIst century, ed. H.J. Ribeiro, 111-126. Coimbra: Imprensa de Universidade de Coimbra.

Mackenzie, J. 1990. Four dialogue systems. Studia Logica 49: 567-583.

Tannen, D. 2002. Agonism in academic discourse. Journal of pragmatics 34: 1651-1669.

van Eemeren, F.H., and R. Grootendorst. 1992. Argumentation, communication, and fallacies: A pragmadialectical perspective. Hillsdale NJ: Lawrence Erlbaum.

van Eemeren, F.H., and R. Grootendorst. 2004. A systematic theory of argumentation. The pragmadialectical approach. Cambridge: Cambridge University Press.

van Eemeren, F.H., and P. Houtlosser. 1999. Delivering the goods in critical discussion. In Proceedings of the fourth international conference of the international society for the study of argumentation, ed. F.H. van Eemeren, R. Grootendorst, J.A. Blair, and C.A. Willard, 163-167. Amsterdam: Sic Sat.

van Eemeren, F.H., and P. Houtlosser. 2002. Strategic manoeuvring in argumentative discourse: A delicate balance. In Dialectic and rhetoric: The warp and woof of argumentation analysis, ed. F.H. van Eemeren and P. Houtlosser, 131-159. Dordrecht: Kluwer.

van Eemeren, F.H., and P. Houtlosser. 2005. Theoretical construction and argumentative reality: An analytical model of critical discussion and conventionalised types of argumentative activity. In The uses of argument: Proceedings of a conference at McMaster University, ed. D. Hitchcock, 75-84. Hamilton: Ontario Society for the Study of Argumentation.

van Eemeren, F.H., B. Garssen, and B. Meuffels. 2009. Fallacies and judgments of reasonableness: Empirical research concerning the pragma-dialectical discussion rules. Dordrecht: Springer.

van Eemeren, F.H., P. Houtlosser, C. Ihnen, and M. Lewiński (2010) Contextual considerations in the evaluation of argumentation (forthcoming).

Walton, D.N. 1998. The new dialectic: Conversational contexts of argument. Toronto: University of Toronto Press.

Walton, D.N., and E.C.W. Krabbe. 1995. Commitment in dialogue. Basic concepts of interpersonal reasoning. Albany: State University of New York Press. 